DOI: https://doi.org/10.24164/prosiding.v3i1.24

\title{
TEKS DAN KONTEKS \\ DALAM JEJAK BUDAYA TAKBENDA \\ STUDI KASUS: BABASAN DAN PARIBASA SUNDA
}

\author{
Text and Context in the Tract of Intangible Culture \\ Case Study: Sunda Babasan and Paribasa
}

\author{
Yayat Hendayana
}

Universitas Pasundan

Jalan Setiabudi No 199 - Bandung

E-mail: yayat.hendayana@gmail.com

\begin{abstract}
Babasan (parables) and paribasa (proverbs) contained in the Sundanese language, is an intangible cultural heritage that is still alive and used by Sundanese people to this day. Sundanese is a group of Austronesian languages, which has a close relationship with the AustroAsian language family. Both of them are referred to as the Austropic language family. Sundanese is a member of a large and very important family of languages in the world. Sundanese language recognizes three stages of development, namely Sundanese Buhun (ancient), Classical Sundanese (transitional) and Sundanese Kiwari (Present), namely Sundanese which began to be used since the 1900s, when Dutch colonialism began to launch political policies of reciprocation (ethical politics). Since that time the beginning of the development of parables and proverbs in Sundanese, which is still used today. The babasan and paribasa are texts created by the ancestors (Sundanese) at that time, which of course are adapted to the needs of their times, with their context. Times have changed. The context also changes. Babasan and paribasa products of Sundanese ancestors, of course, are not all suitable for use in the present, which has changed much from the past. The thought that all past products are valuable (very high quality) is not entirely true. Concerning the chapters and paribasas which are products of the past, gradual adjustment steps must be taken so that they can be applied in today's daily life. The phased steps are: (1) reselection, (2) redescription, (3) reorientation, and (4) re-implementation.
\end{abstract}

Keywords: text and context, past and present, adjustments.

\begin{abstract}
AbSTRAK
Babasan (perumpamaan) dan paribasa (peribahasa) yang terdapat dalam bahasa Sunda, merupakan warisan budaya takbenda yang masih tetap hidup dan digunakan oleh masyarakat Sunda hingga saat ini. Bahasa Sunda termasuk rumpun bahasa-bahasa Austronesia, yang mempunyai hubungan erat dengan rumpun bahasa Austro-Asia. Keduanya disebut sebagai rumpun bahasa Austris. Bahasa Sunda merupakan anggota dari keluarga bahasa yang besar dan penting sekali di dunia. Bahasa Sunda mengenal tiga tahapan perkembangan, yaitu bahasa Sunda Buhun (kuno), bahasa Sunda Klasik (peralihan) dan bahasa Sunda Kiwari (Masa Kini), yaitu bahasa Sunda yang mulai digunakan sejak tahun 1900-an, ketika kolonialisme Belanda mulai melancarkan politik balas budi (politik etis). Sejak saat itulah awal mula berkembangnya perumpamaan dan pribahasa dalam bahasa Sunda, yang masih tetap digunakan di zaman kini. Babasan dan paribasa tersebut merupakan teks yang diciptakan oleh para leluhur (Sunda)
\end{abstract}


ketika itu, yang sudah tentu disesuaikan dengan kebutuhan zamannya, dengan konteksnya. Zaman sudah berubah. Konteks pun berubah pula. Babasan dan paribasa produk para leluhur Sunda itu tentu saja tidak semuanya cocok untuk digunakan pada masa sekarang, yang sudah jauh berubah dari masa lalu. Pikiran bahwa semua produk masa lalu bersifat adiluhung (berkualitas sangat tinggi) tidak sepenuhnya benar.. Terhadap babasan dan paribasa yang merupakan produk masa lalu itu harus dilakukan langkah-langkah penyesuaian bertahap agar dapat diterapkan dalam kehidupan sehari-hari zaman kini. Langkah-langkah bertahap itu ialah: (1) reseleksi, (2) redeskripsi, (3) reorientasi, dan (4) reimplementasi.

Kata kunci: teks dan konteks, masa lalu dan masa kini, penyesuaian

\section{PENDAHULUAN}

\section{Bahasa Sunda, Rumpun Bahasa Austronesia}

$\mathrm{B}_{\mathrm{b}}^{\mathrm{a}}$ ahasa Sunda termasuk rumpun bahasabahasa Austronesia, sebuah rumpun yang areal penyebarannya sangatlah luas. Sebelum terjadi eksodus orang-orang Eropa ke Amerika dan Australia, rumpun bahasabahasa Austronesia bahkan mempunyai areal panyebaran yang terluas di dunia. Areal penyebarannya meliputi pulau Madagaskar di sebelah barat, Pulau Paskah dekat Amerika Selatan di sebelah timur, Taiwan di sebelah utara, dan Selandia Baru di sbelah selatan. Menurut Elis Suryani N.S., dalam tulisannya tentang Sejarah Perkembangan Bahasa di Tatar Sunda, yang merupakan bagian dari buku antologi mengenai Sejarah Kebudayaan Sunda (2011), wilayah Austronesia mencakup Madagaskar, Indonesia, Malaysia, Filipina, Taiwan, kepulauan-kepulauan Melanesia, Mikronesia dan Polinesia, termasuk Selandia Baru. Rumpun bahasa-bahasa Austronesia mempunyai hubungan yang erat dengan bahasa-bahasa dari rumpun Austro-Asia. Kedua rumpun itu disebut rumpun bahasabahasa Austris. Dengan demikian, bahasa Sunda merupakan rumpun dari bahasabahasa Austris, yang merupakan gabungan dari rumpun Austronesia dengan rumpun Austro-Asia. Oleh karena itu, bahasa Sunda merupakan salah satu bahasa dari rumpun bahasa-bahasa Austronesia dan juga AustroAsia, yang kedua-duanya memiiki areal penyebaran yang sangat luas (Suryani, 2011).

Bahasa Sunda mempunyai hubungan yang sangat erat dengan bahasa Melayu, yang sekarang berkembang menjadi bahasa Indonesia yang digunakan di Indonesia, dan bahasa Malaysia yang digunakan di Malaysia. Selain dengan bahasa Melayu, bahasa Sunda pun erat pula hubungannya dengan bahasa Jawa. Dengan kedua bahasa itu, yaitu bahasa Melayu dan bahasa Jawa, hubungan bahasa Sunda tidak hanya secara struktural belaka, melainkan juga penggunaan kosakata yang sama atau hampir sama dari ketiga bahasa tersebut. Bahasa Sunda yang merupakan salah satu bahasa yang hidup di Indonesia, tentu berkembang secara dinamis sesuai dengan perkembangan zaman. Di masa awal perkembangannya, bahasa Sunda sangat mungkin dipengaruhi oleh bahasa-bahasa dari rumpun Austronesia lainnya, sebagaimana rumpun bahasabahasa Austronesia lainnya dipengaruhi perkembangan bahasa Sunda.

Perkembangan sebuah bahasa tidak bisa dipisahkan dari perkembangan aksara yang digunakan dalam bahasa tersebut. Perkembangan bahasa Sunda tentu tidak bisa dipisahkan dari aksara yang digunakan. Aksara merupakan alat perekam dari suara-suara yang dilontarkan bahasa, baik 
secara lisan maupun tulisan. Melalui sajian aksara, kita menjadi tahu informasi apakah yang dimaksudkan oleh seorang pengguna bahasa. Aksara pulalah yang bisa menjadi sarana komunikasi antarpara pengguna sebuah bahasa secara tertulis. Dalam batas tertentu, aksara dapat dijadkan pembatas antara zaman prasejarah dengan zaman sejarah. Sebelum sekelompk masyarakat mengenal aksara, zaman itu disebut zaman prasejarah, sedangkan apabila kelompok masyarakat tersebut telah mengenal aksara, maka dapatlah dikatakan bahwa kelompk masyarakat tersebut telah memasuki zaman sejarah.

Pada zaman Kerajaan Tarumanagara, sekitar abad IV Masehi, aksara sudah dikenal di Tatar Sunda. Namun sulit dibuktikan karena tak ditemukan tinggalan budayanya. Naskah-naskah dari zaman Tarumanagara (abad ke IV sampai ke VII Masehi) tdak dapat dilacak lagi karena bahan-bahan untuk menulis naskah seperti daun, kulit, dan kertas, mudah sekali rusak. Sepanjang sejarahnya, di Tatar Sunda sudah digunakan tujuh jenis aksara secara berganti-ganti, yaitu Pallawa, Pranagari, Sunda Kuno, Jawa (Carakan), Arab Pegon, Cacarakan, dan Latin. Mengacu Undang Darsa dkk, Elis Suryani NS mengatakan:

Ketujuh aksara tersebut dipakai sejak abad ke-5 Masehi hingga sekarang, dengan perincian: aksara Pallawa dan Pranagari (abad ke-5 Masehi hingga abad ke-7 Masehi, \pm selama 3 abad), aksara Sunda Kuno (abad ke-14 hingga abad ke-18 Masehi, \pm selama 5 abad), aksara Jawa atau Carakan (abad ke11 dan abad ke-17 hingga abad ke19 Masehi, \pm selama 4 abad), aksara Arab atau Pegon (abad ke-17 hingga pertengahan abad ke-20 Masehi, \pm selama 3 abad), aksara Cacarakan (abad ke19 hingga pertengahan abad ke-20 Masehi, \pm selama 2 abad) dan huruf Latin (akhir abad ke-19 hingga sekarang, \pm selama 2 abad. (hal. 88).

Menurut peniliti perkembangan bahasa dan aksara Sunda dari Jepang, Prof. Mikihiro Moriyama, yang juga dikutip Elis, "Sebelum aksara Latin diperkenalkan oleh Belanda di wilayah penutur bahasa Sunda pada abad ke19, bahasa Sunda sudah ditulis dlam aksara Arab (Pegon) selain dalam aksara Jawa.

\section{HASIL DAN PEMBAHASAN}

\section{Sejarah Perkembangan Bahasa Sunda}

Perkembangan sebuah bahasa sangat berkaitan dengan perkembangan budaya masyarakat penutur bahasa tersebut. Perkembangan bahasa Sunda sejalan dengan perkembangan kebudayaan Sunda. Masyarakat Sunda tentu tidak hidup di sebuah ruang kosong. Masyarakat Sunda tentu harus berhubungan dan berkomunikasi dengan bangsa-bangsa dan/atau suku bangsa-suku bangsa lain. Komunikasi itu menyebabkan terjadinya kontak budaya. Kebudayaan-kebudayaan asing yang memengaruhi kebudayaan Sunda adalah pengaruh budaya Hindu-Budha, budaya Islam, kebudayaan Mataram (Jawa), dan kebudayaan Barat. Pengaruh budaya asing itu tidak mengubah budaya dasar yag sudah dimiliki masyarakat Sunda, melainkan digabung, dan penggabungan itu disesuaikan dengan kebutuhan masyarakat sesuai degan perkembangannya.

Sesuai dengan tahapan penggunaannya, perkembangan bahasa Sunda dapat dibagi menjadi tiga periode, yaitu:

1. Bahasa Sunda Zaman Bihari/Buhun 
2. Bahasa Sunda Zaman Klasik/Peralihan

3. Bahasa Sunda Zaman Kiwari/Masa Kini

\section{- Bahasa Sunda Zaman Bihari/ Buhun}

Bahasa Sunda Zaman Bihari/Buhun adalah bahasa Sunda yang berkembang di sekitar abad XVI Masehi, ketika di Tatar Sunda telah berdiri beberapa kerajaan, antara lain Tarumanagara, Salakanagara, Galuh, Sunda, Pajajaran dan sebagainya. Bahasa Sunda yang digunakan oleh masyarakat penutur bahasa Sunda ketika itu sama dengan bahasa Sunda yang tertulis dalam prasastiprasasti atau naskah-naskah Sunda Buhun. Adapun bahasa yang digunakan untuk menulis prasasti atau nasah-naskah buhun adalah bahasa Sangsekerta, sedangkan aksara yang dugunakan adalah Pallawa/Paranagari. Selain itu juga aksara Carakan/Jawa dan aksara Sunda Buhun. Digunakannya bahasa dan aksara Sunda Buhun dapat dibaca pada prasasti Geger Hanjuang di Galunggung. Prasasti tersebut hanya terdiri dari tiga baris, yaitu:

tra ba i gunna apuy nasta

gomati sakakala rumatak

disusu (k) ku batari hyang pun

Terjemahannya:

dina poe ka-13 bulan Badra taun 1033

Saka Rumatak disusuk (dikamaliran)

ku Batari Hyang. (Pada hari ke-13 bulan Badra tahun 1033 Saka Rumatak (selesai) disusuk oleh Batari Hyang)

Secara umum, bahasa Sunda Buhun terdapat pada prasasti-prasasti seperti batu bertulis yang terdapat di Astanagede, Kawali, Kabupaten Ciamis. Ada enam buah batu bertulis dilokasi Astanagede itu. Dua buah batu bertulis di antaranya, berisi tulisan Sanghyang Linggahyang dan Sanghyang Linggabingba. Diduga, kedua batu bertulis tersebut merupakan tanda penghrmatan terhadap nama kedua tokoh tersebut. Dua buah batu bertulis lainnya disebut sebagai prasasti Kawali I dan prasasti Kawali II. Menurut Elis, Prasasti Kawali I merupakan prasasti pertama yang ditulis dengan menggunakan aksara Sunda dan bahasa Sunda Buhun. Selanjutnya, aksara dan bahasa Sunda Buhun digunakan mulai dari Kerajaan Salakanagara hingga Kerajaan Pajajaran. Pada masa Kerajaan Pajajaran (1482-1579) Bahasa Sunda Buhun telah digunakan dalam berbagai bidang, mulai dari bidang kenegaraan, keagamaan, kesenian, serta komunikasi bagi kepentingan kehidupan sehari-hari. Jejak Bahasa Sunda Buhun dapat kita temukan dalam naskah Carita Parahyangan. Dalam naskah itu jelas sekali bahwa banyak kosakata yang dipergunakan pada bahasa Sunda Buhun yang tidak digunakan lagi dalam bahasa Sunda Kiwari (Masakini).

\section{- Bahasa Sunda Zaman Klasik (Peralihan)}

Di zaman Kerajaan Pajajaran, bahasa Sunda (Buhun) digunakan oleh masyarakat, bahkan oleh lingkungan kerajaan untuk brkmunikas satu sama lain. Namun setelah kerajaan Pajajaran runtuh oleh kekuatan Islam pada tahun 1579, kosakata bahasa Sunda Buhun sudah bertambah dengan kosakata bahasa Arab dan juga bahasa Jawa. Bahasa Sunda Buhun dapat dikatakan tergeser penggunaannya. Hanya masyarakat Sunda di pedesaan yang masih setia menggunakan bahasa Sunda Buhun. Adapun di lingkungan pesantren, penggunaan bahasa Arab tumbuh subur setelah kekuatan Islam berkuasa. Sedangkan di lingkungan sekolah umum serta di lingkungan kerajaan, penggunaan bahasa Jawa tumbuh subur pula. 
Pada zaman itu, pengaruh budaya Jawa kepada masyarakat Sunda sedemikian rupa kuatnya. Masyarakat Sunda yang sebelumnya tidak mengenal unggah-ungguh dalam penggunaan bahasanya dalam berkomunikasi, harus menggunakan undak usuk bahasa dalam berkomunikasi. Setelah itu, masyarakat Sunda yang egaliter, berubah menjadi feodalistik. Merujuk hasil penelitian Coolsma, Elis Suryani NS menyebutkan:

"Hasil penelitian Coolsma
membuktikan bahwa undak-usuk
Basa Sunda merupakan pengaruh dari
bahasa Jawa, karena bahasa Sunda
sebelum dipengaruhi bahasa Jawa tidak
mengenal tingkatan bahasa atau undak-
usuk bahasa seperti yang dikenal dalam
masyarakat Jawa"(hal. 125)

Untuk menguatkan hasil penelitiannya, Coolsma mencontohkan naskah-naskah Sunda buhun berbahan lontar atau nipah yang menggunakan bahasa Sunda Bihari (Buhun). Salah satu teks naskah abad ke-16 Masehi yang berjudul Kawih Pamungkas ijadikan contoh oleh Coolsma tentang belum dikenalnya undak-usuk basa dalam bahasa Sunda Buhun. Teks itu berbunyi:

"Ini kawih panyaraman, pikawiheun ubar keueung, ngaranna pangereg darma, ngawangun rasa sorangan, hawakaneun sang sisya, nu huning Sewaka Darma. Anaking mulah mo yatna-yatna, reungeu sabda sang pandita, ingetkeun hayuwa lali, teher nging ngenak-ngenak rasa, ngaranna ngapakan tali. Ingetkeun na dasasila, iseuskeun na panca sakti, iyan ia ningkahkeun raga mayahkeun sarira, ngalekskeun suku tangan..."

Bahasa Sunda Zaman Klasik (Peralihan) merupakan pengembangan dari bahasa Sunda Zaman Bihari (Buhun). Hal tersebut tampak antara lain dalam teks Carita Waruga Guru. Kosakata yang digunakan dalam teks tersebut bukanlah kosakata yang arkais (kuno) sebagaimana terdapat dalam bahasa Sunda Buhun. Bahasa Sunda Zaman Klasik (Peralihan) sangat dipengaruhi oleh bahasa Jawa dan bahasa Melayu. Sebaliknya, banyak pula kosakata bahasa Sunda Zaman Peralihan yang diadopsi oleh kedua bahasa tersebut, baik untuk kepentingan agama maupun pemerintahan. Namun dominasi pengaruh terhadap bahasa Sunda Zaman Peralihan dalam bidang agama, tetaplah dimiliki oleh bahasa Arab. Elis Suryani NS mengemukakan bahwa:

"Zaman Klasik masih terus berlangsung hingga sekitar tahun 1800-1900 meskipun masyarakat Sunda sudah mengenal aksara Laten (Latin) dan mengalami perubahan. Itu sebabnya Zaman Klasik disebut juga Zaman Peralihan. Karena di satu sisi masyarakat masih banyak berpegang kepada halhal yang berbau Islam dan Jawa, sesuai dengan aksara yang digunakannya. Namun di pihak lain, sudah ada pengaruh Barat melalui aksara Latin yang dikenalkannya, meskupin belum begitu berkembang secara menyeluruh." (hal.126)

\section{- Bahasa Sunda Zaman Kiwari (Masa Kini)}

Bahasa Sunda Zaman Kiwari (Masa Kini) dimulai penggunaannya sekitar tahun 1900 ketika kolonialisme Belanda mulai melancarkan Politik Etis, yaitu plitik balas budi kepada masyarakat pribumi yang telah diperas hasil-buminya selama ratusan tahun. Sesungguhnya, yang disebut Politik Etis itu tak lain dari kebijakan pemerintah kolonial yang telah dilakukan sebelumnya, yang 
kemudan dilanjutkan kembli pada tahun 1900. Melalui Pliik Etis, pemerintahan kolonial Belanda mendirikan berbagai macam sekolah untuk kaum pribumi, Sekolah Guru, Sekolah Menak, dan OSVIA. Tentu saja sekolah-sekolah itu didirikan untuk kaum ningrat, yaitu masyarakat Sunda pribumi yang termasuk golongan menengah ke atas. Untuk masyarakat kelas bawah, pemerintah penjajah Belanda mendirikan pula Sekolah Kelas I dan Sekolah Kelas II. Bahkan pada tahun 1907 pemerintah Belanda mendirikan pula Sekolah Desa. Didirkannya sekolah-sekolah itulah yang menyebabkan penggunaan bahasa Sunda di masyarakat tumbuh kembali dengan amat suburnya. Karya sastra, baik dari khazanah kesusasteraan lama seperti wawacan dan guguritan, maupun karya-karya baru, diterbitkan.

Sekalipun merupakan perkembangan dari bahasa Sunda yang digunakan sebelumnya, yaitu bahasa Sunda Buhun yang berkembang menjadi bahasa Sunda Klasik (Peralihan), penggunaan bahasa Sunda sejak tahun 1900 merupakan bahasa Sunda yang berkembang sedemikian rupa, sehingga kosakata yang digunakannya merupakan kosakata yang nyaris baru. Kendati pemerintah Jepang menggantikan kedudukan Belanda sebagai penjajah. Penggunaan bahasa Sunda di tengah-tengah masyarakat terus berkembang. Penjajah Jepang bahkan memberikan prioritas kepada bahasa Sunda untuk berkembang dengan mendirikan suratkabar seperti Pasoendan pada tahun 1917, Poesaka Senda (1923), dan Sipatahoenan (1923). Keberadaan suratkabar-suratkabar inilah, di samping banyaknya karya sastra yang terbit, yang telah menyebabkan bahasa Sunda Zaman Kiwari (Masa Kini) berkembang pesat.
Dalam masa penggunaan bahasa Sunda Zaman Kiwari (Masa Kini), berkembang pulalah penggunaan perumpamaan (babasan) dan paribasa (peribahasa) dalam masyarakat. Sangat boleh jadi babasan dan paribasa itu telah ada dalam penggunaan bahasa Sunda Zaman Buhun (Kuno) dan bahasa Sunda Zaman Klasik (Peralihan), namun kurang diicarakan dalam perbincangan masyarakat. Babasan dan paribasa mulai berkembang dan menjadi perbincangan masyarakat dalam kehidupan sehari-hari justru setelah berkembangnya penggunaan bahasa Sunda Zaman Kiwari (Masa Kini). Di masa penggunaan bahasa Sunda Zaman Kiwari diterbitkan buku-buku tentang babasan dan paribasa, antara lain 700 Paribasa Sunda karya Gandasudirdja, 1000 Babasan jeung Paribasa Sunda karya Drs. Budi Rahayu Tamsyah dkk., Babasan jeung Paribasa Sunda karya Drs. Tatang Sumarsono (Sumarsono, 2001). Para pengarang buku babasan dan paribasa itu seolah-olah berlmba-lomba untuk saling menunjukkan bahwa buku karangannya memuat babasan dan paribasa lebih lengkap dari buku karya pengarang lain. Pembicaraan tetang babasan dan paribasa itu menjadi kian semarak setelah diterbitkan pula berbagai buku Kamus Basa Sunda.

Perumpamaan (babasan) dan peribahasa (paribasa) merupakan produk yang dihasilkan dari penggunaan bahasa. Perumpamaan dan peribahasa merupakan hasil kreasi para leluhur pengguna bahasa tersebut. Para penutur bahasa Sunda melahirkan perumpamaan dan peribahasa dalam bahasa Sunda. Oleh para penutur bahasa Sunda, yaitu umumnya masyarakat Sunda, perumpamaan dan peribahasa merupakan produk leluhur yang harus diposisikan sebagai warisan budaya. Oleh karena tidak merupakan warisan budaya yang 
berwujud dalam bentuk benda (tangible), maka perumpamaan dan peribahasa itu dapat digolongkan sebagai warisan budaya takbenda (intangible).

\section{Problem Babasan dan Paribasa}

Terhadap warisan budaya takbenda, kajian terhadap nilai yang terkandung di dalamnya lebih mengemuka ketimbang kajian fisik, seperti terhadap warisan budaya benda. Di tengah-tengah masyarakat Sunda sekarang ini terdapat kecenderungan yang menganggap segala produk budaya takbenda para leluhur selalu bernilai tinggi. Begitu pula halnya pandangan terhadap babasan dan paribasa. Anggapan semacam itu timbul dari cara pandang sebagian masyarakat Sunda yang enganggap Sunda masa lalu itu sebagai Sunda yang tata tengtrem kerta raharja, rea ketan rea keton. Dalam anggapan sebagian masyarakat, zaman Kerajaan Pajajaran adalah zaman ketika rakyat hidup berkecukupan, adil-makmur loh jinawi, karena dipimpin oleh seorang raja yang maha adil bijaksana. Bagi anggapan sebagian masyarakat Sunda, hidup di zaman Pajajaran adalah hidup yang ideal. Anggapan itu timbul dari situasi kehidupan di zaman kini yang bagi sebahagian masyarakat Sunda, mungkin juga bagi sbagian masyarakat suku-bangsa lain, kehidupan sekarang ini sungguh berat. Kehidupan sehari-hari tidaklah seindah yang dibayangkan. Situasi kehidupan nyata yang dialami sehari-hari sungguh berbeda keadaannya dengan dongeng-dongeng yang dikisahkan di waktu senggang oleh para tetua kita. Romantisme pada keagungan masa lalu tetap mendominasi benang merah perjalanan kebudayaan Sunda.

Cara pandang bahwa hidup di masa lalu serba indah, berpengaruh pula terhadap sikap budaya. Sebagian masyarakat, khususnya masyarakat Sunda, menganggap bahwa produk budaya masa lalu, apalagi produk budaya yang bersifat takbenda, selalu bernilai luhur. Menurut Al Wasilah, "Oleh Urang Sunda, ungkapan, petatah-petitih, dan peribahasa yang merupakan cermin budaya komunitas itu cenderung dibanggabanggakantanpasikapkritis."(Wasilah,2006: 37). Babasan dan paribasa yang dibuat para leluhur harus selalu disikapi sebagai produk budaya yang bernilai luhur, yang adiluhung. Padahal tentu tidaklah begitu. Babasan dan paribasa yang dibuat para leluhur adalah teks yang pada waktu pembuatannya tentu dipengaruhi oleh keadaan sekelilingnya, oleh zamannya, oleh konteksnya. Ketika dibuat, antara teks dan konteks tentulah saling berpengaruh. Teks yang dibuat para leluhur dalam bentuk babasan dan paribasa sudah tentu disesuaikan dengan konteksnya. Oleh karena itu, tentu ada teks yang cocok diterapkan dalam konteks sekarang ini, ada pula yang tidak. Malah bukan mustahil ada babasan dan/atau paribasa yang secara nilai sangat bertentangan dengan tujuan meraih masa depan.

Oleh karena teks selalu dikaitkan dengan konteks (zamannya), tidak ssemua produk leluhur di zaman lampau cocok untuk diterapkan di masa kini. Terhadap babasan dan paribasa masa lalu itu, harus disikapi secara kritis di zaman sekarang ini. Ada beberapa langkah bertahap yang harus kita lakukan sebelum sampai pada pendapat bahwa babasan dan paribasa yang merupakan warisan budaya takbenda itu cocok untuk kita gunakan di zaman sekarang. Langkah-langkah bertahap itu ialah (1) reseleksi, (2) redeskripsi, (3) reorientasi, (4) reimplementasi. Satu demi satu dari empat langkah bertahap itu akan diuraikan satu demi satu di bawah ini. 


\section{(1) Reseleksi}

Langkah ini merupakan langkah untuk memilah-milah dan memilih-milih kembali mana babasan dan paribasa yang bernilai tinggi, yang hanya bernilai saja (tapi tidak tinggi), dan mana yang tidak bernilai sama sekali, yang kalau dipaksa untuk diterapkan justru akan menghambat kemajuan masyarakat (Sunda). Melalui reseleksi, kita aan menemukan mana babasan atau paribasa yang adiluhung (bernilai sagat tinggi). Kita akan menyebut babasan atau paribasa itu adiluhung apabila teks berupa babasan dan paribasa itu dapat diterapkan dalam konteks apapun, dalam keadaan dan zaman apapun. Adapun kita akan menyebut babasan dan paribasa itu bernilai luhung, jika kita mendapati kenyataan bahwa teks berupa babasan dan paribasa itu hanya cocok untuk diterapkan pada zaman ketika teks itu dibuat, dan tidak berarti apa-apa jika diterapkan pada zaman sekarang.

\section{(2) Redeskripsi}

Langkah mendeskripsi ulang ini dilakukan apabila kita berpendapat bahwa secara teks, babasan atau paribasa yang merupakan warisan budaya takbenda itu tetap menarik. Tetapi nilai yang terkandung di balik teks itu justru berbeda dengan kandungan teksnya. Terhadap babasan dan paribasa semacam itu kita dapat memberi deskripsi yang tepat, baik untuk diterapkan di masa lalu atau di masa kini.

\section{(3) Reorientasi}

Di atas telah dikemukakan bahwa timbulnya sikap budaya yang selalu berpendapat bahwa produk budaya takbenda yang diwariskan oleh para leluhur kita selalu bernilai tinggi (adiluhung) justru disebabkan oleh romantisme terhadap kehidupan masa lalu, zaman Tatar Sunda dipimpin oleh raja-raja, yang selalu digambarkan sebagai kehidupan yang ideal. Romantisme terhadap keagungan masa lalu itu harus diubah. Masyarakat Sunda harus berpikiran realistis dalam memandang hari esok, yang mungkin saja akan terasa lebih berat daripada hari ini. Agar anggapan bahwa budaya takbenda produk leluhur masa lalu itu selalu bernilai tinggi, kita harus mengubah orientasi masyakarat Sunda dari nyoreang ka tukang (melamun ke masa lalu) menjadi nyawang ka hareup (memandang ke depan) disertai pikiran kritis serta sikap hidup yang realistis.

\section{(4) Reimplementasi}

Mengonkretkan langkah-langkah yang dikemukakan di atas agar tidak hanya tinggal sebagai angan-angan belaka. Seringkali, rencana yang baik tidak dilaksanakan, namun dibiarkan hanya sebagai rencana belaka, yang akhirnya hanya sekadar menjadi impian semata.

\section{SIMPULAN}

Dari apa yang saya paparkan di atas, saya menarik simpulan bahwa dalam setiap jejak budaya yang mewariskan budaya takbenda, selalu terdapat dua buah aspek, yaitu teks dan konteks. Setiap teks yang lahir senantiasa disesuaikan dengan konteksnya, yang salah satunya adalah lingkungan masyarakat pada zaman ketika teks itu dibuat. Diperlukan langkah penyesuaian dalam berusaha menerapkan warisan budaya 
takbenda masa lalu dengan kondisi kekinian, yang konteksnya sudah jelas-jelas berbeda. Namun, sikap yang meniadakan hubungan antara teks dan konteks dalam pewarisan budaya takbenda sangat mungkin merupakan sikap dari semua suku bangs- suyang ada di nusantara.

\section{DAFTAR PUSTAKA}

Al Wasilah, Chaedar. 2006. Pokoknya Sunda. Bandug:UPI

Sumarsono, Tatang. 2001. Babasan jeung Paribasa Sunda. Bandung: Geger Sunten

Suryani, Elis. 2011. Sejarah Prkembangan Aksara dan Bahasa Sunda dalam buku Sejarah Kebudayaan Sunda. Bandung: YMSI

\section{HASIL DISKUSI}

\section{Pertanyaan}

\section{Dr. Retno Purwanti, M.Hum (Balai Arkeologi Sumatera Selatan)}

Saya kurang faham mengenai Bahasa Sunda, namun yang saya tahu seperti ini Pak, di tatar sunda berkembang beberapa kerajaan yang masa kuno ada Kesultanan Banten, Sumedang, Cirebon. Nah dalam sejarah perkembangan institusi kerajaan berbeda ini, apakah masa- masa kemudian ini ada persinggungan? adakah saat Bahasa Jawa lebih dominan digunakan dibandingkan dengan Bahasa Sunda atau Bahasa Jawa ini hanya dipakai di lingkungan keraton saja?

\section{Jawaban}

1. Seperti lazimnya di berbagai daerah, kebudayaan selalu saja timbul tenggelam seperti halnya dengan kerajaan. Kerajaan-kerajaan dengannamaWarman (Mulawarnan, Purnawarman) itu pasti kerajaan dengan pengaruh HinduBudha. Kerajaan yang menggunaan penaaman Kerajaan Galuh dan Kerjaan Sunda sudah pasti ada pengaruh dari agama asli Sunda. Kerjaan-kerajaan yang menggunakan nama lokasi seperti Kerajaan Cirebon, Sumedang Larang itu kerajaan baru yang sudah mendapat pengaruh dari Jawa. Misalnya Kerajaan Cirebon bertengkar hebat dengan Sumedang Larang tetapi karena pengaruh kekuasaan politik Jawa yang begitu besar terhadap Cirebon, sehingga Cirebon menganggap Sumedang Larang sebagai musuh. Sudah pasti perubahan itu akan menyebabkan kebudayaan lama terpaksa harus berhubungan dengan kebudayaan baru. Saya kira itu. Terkait dengan Bahasa Sunda, saya kira kata "aing" itu tidak kasar pada masa itu, di Bali juga masih digunakan kata "aing". 